\title{
Meningkatnya Repeat Purchasedengan Content Marketing dan Brand Performance Melalui Customer Engagement Pada Konsumen Produk Fashion Merek Uniqlo
}

\author{
Dyah Ika Kirana Jalantina*, Maria Magdalena Minarsih \\ Fakultas Ekonomi, Universitas Pandanaran, Semarang, Indonesia \\ Email: dyah.ika@unpand.ac.id \\ Email Penulis Korespondensi: dyah.ika@unpand.ac.id \\ Submitted: xx/11/2021; Accepted: 29/11/2021; Published: 30/11/2021
}

\begin{abstract}
Abstrak-Penelitian ini bertujuan untuk menganalisis dan menguji pengaruh content marketing dan brand performance terhadap repeat purchase dengan customer engagement sebagai variabel intervening pada konsumen produk pakaian merek Uniqlo.Dengan content marketing yang menarik, relevan dan memahami target pasar, serta brand performance yang kuat dalam menempati posisi merek di pasar akan menciptakan keterikatan bagi konsumen dalam hal kesadaran merek sehingga konsumen akan melakukan repeat purchase. Metode yang digunakan adalah analisis regresi berganda. Data dikumpulkan menggunakan kuesioner. Sampel pada penelitian ini diambil sebanyak 100 responden dengan usia lebih dari atau sama dengan 17 tahun yang pernah melakukan pembelian produk fashion merek Uniqlo. Hasil penelitian ini menunjukkan bahwa content marketing berpengaruh positif dan signifikan terhadap customer engagement, brand performanceberpengaruh positif dan signifikan terhadap customer engagement, content marketingberpengaruh positif dan signifikan terhadap repeat purchase, brand performanceberpengaruh positif dan signifikan terhadap repeat purchase, customer engagement berpengaruh positif dan signifikan terhadap repeat purchase.
\end{abstract}

Kata Kunci: Pemasaran Konten; Kinerja Merek; Keterlibatan Pelanggan; Pembelian Berulang

Abstract-This study aims to analyze and examine the effect of content marketing and brand performance on repeat purchases with customer engagement as an intervening variable on consumers of Uniqlo brand clothing products. With content marketing that is interesting, relevant and understands the target market, as well as a strong brand performance in occupying a brand position in the market, it will create an attachment for consumers in terms of brand awareness so that consumers will make repeat purchases. The method used is multiple regression analysis. Data were collected using a questionnaire. The sample in this study was taken as many as 100 respondents with an age of more than or equal to 17 years who had purchased Uniqlo brand fashion products. The results of this study indicate that content marketing has a positive and significant effect on customer engagement, brand performance has a positive and significant effect on customer engagement, content marketing has a positive and significant effect on repeat purchases, brand performance has a positive and significant effect on repeat purchases, customer engagement has a positive and significant impact on repeat purchases. significant to repeat purchases.

Keywords: Content Marketing; Brand Performance; Customer Engagement; Repeat Purchase

\section{PENDAHULUAN}

Teknologi informasi dan internet yang semakin berkembang saat ini membuat ketergantungan dari masyarakat dalam hampir semua dimensi kehidupannya antara lain dengan adanya media sosial, berita online, dan juga informasi untuk belanja atau membeli pakaian secara online.Perkembangan itu terbukti dengan adanya peningkatan pengguna internet dari waktu ke waktu, seolah tanpa internet maka kehidupan akan terhenti. Kebutuhan akan internet menjadi kebutuhan pokok masyarakat yang harus selalu terpenuhi.

Berdasarkan survey Asosiasi Penyelenggara Jasa Internet Indonesia (APJII) maka pada tahun 2019-2020 terdapat total pengguna internet di Indonesia sebanyak 196,7 pengguna, naik 8,9 persen dari survey yang dilakukan pada tahun 2018. Hal ini juga sebagai dampak dari pandemi Covid-19 yang melanda dunia termasuk Indonesia sehingga memaksa masyarakat beralih dari dunia offline ke onlineyang pada akhirnya masyarakat menjadi semakin familiar dan juga nyaman. Hal ini juga merambah ke dunia pemasaran dimana saat ini metode pemasaran secara online lebih banyak digunakan para pelaku bisnis untuk memasarkan produknya karena dinilai lebih efektif, efisien dan juga dapat menjangkau seluruh dunia secara global. Pemasaran secara tradisional sendiri menjadi semakin tidak efektif.

Salah satu pendekatan dari strategi pemasaran online strategis untuk lebih menarik konsumen dan mencapai target pasaradalah dengan menggunakan content marketing. Dengan content marketing ini pemasar harus dapat membuat dan mendistribusikan konten yang relevan, bertanggung jawab dan bermutu agar dapat menarik konsumen.

Secara khusus content marketing yang digunakan pemasar mempunyai kegunaan diantaranya adalah untuk meningkatkan volume penjualan, meminimalisir biaya, menimbulkan loyalitas konsumen dan memaksimalkan keuntungan.

Content marketing yang efektif salah satunya adalah apabiladapat menimbulkan customer engagementyang merupakan interaksi atau komunikasi yang baik antara produsen atau pemilik merek dengan konsumen sasarannya. Customer engagement dapat terjadi karena suatu pengalaman atau pengetahuan yang dirasakan konsumen terhadap suatu merek produk yang telah dipilih. 
Konsumen yang terlibat dalam content marketingadalah penting bagi produsen karena hal tersebut dapat menciptakan keyakinan konsumen akan suatu produk sehingga akan menghasilkan tindakan konsumen yang positif seperti adanya keputusan pembelian bahkan kemudian terjadinya pembelian ulang atau repeat repurchase.(Dharmayanti \& Juventino, 2020)Konsumen akan tertarik dan rela membayar lebih untuk suatu merek apabila secara emosional telah mempunyai ikatan terhadap merek tersebut. Oleh karenanya perusahaan harus menjaga customer engagement terhadap konten yang dibuat.

Customer engagement juga memberikan pengaruh yang besar untuk meningkatkan repeat purchase dengan biaya minimal serta dapat menjangkau konsumen yang menjadi target pasar suatu perusahaan atau brand (Sanjaya, 2020).

Selain content marketing yang dapat menimbulkan customer engagement adalah brand performance. Salah satu faktor berhasilnya suatu perusahaan adalah dengan membangun keunggulan merek (brand) yang dapat bersaing melalui kinerja merek (brand performance), (Wijaya \& Dharmayanti, 2019). Merek menciptakan pengaruh terhadap jumlah penjualan dalam satu periode waktu (bulanan, tahunan) dan memperoleh pangsa pasar yang lebih luas.

Penilaian konsumen terhadap kualitas suatu merek produk dapat mengindikasikan seberapa bagusbrand performance (kinerja merek) tersebut secara obyektif. Konsumen dapat membedakan produk melalui merek dari tiap produsen yang berlainan. Brand performance adalah juga bagaimana suatu produk atau jasa dapat memenuhi dan memuaskan kebutuhan dan keinginan konsumen. Dengan demikian maka apabila konsumen menganggap brand performance sudah bagus maka tidak akan berpindah ke merek lain.

Berbagai daya upaya yang dilakukan oleh perusahaan atau merek pasti bertujuan agar tercapainya keberadaan merek secara berkesinambungan di pasar. Salah satu keadaan yang menunjukkan bahwa suatu merek berkesinambungan adalah terjadinya repeat purchase (pembelian ulang). Repeat puchase merupakan salah satu aspek yang menjadi parameter keberhasilan suatu merek di pasar (Sanjaya, 2020).

Konsumen yang melakukan repeat purchase biasanya akan membelanjakan uangnya lebih banyak daripada konsumen yang baru mengenal suatu merek. Selain itu repeat purchase konsumen juga pasti akan menaikkan laba dari suatu merek dan menimbulkan efisiensi biaya daripada konsumen baru.

Setiap merek atau perusahaan akan berusaha mendapatkan repeat purchase dari setiap konsumen, begitu juga perusahaan ritelfashion merek Uniqlo. Uniqlo didirikan di Jepang pada tahun 1984 dan dibuka di Indonesia pada tahun 2013 dibawah perusahaan Fast Retailing Co, Ltd. Konsep tokonya adalah suatu gudang yang sangat besar dengan pilihan konstan dan produknya adalah fashion untuk kaum muda dengan model kekinian dan harga terjangkau. Saat ini telah ada 27 toko di 19 kota besar di Indonesia.

Uniqlo sangat inovatif dalam membuat produk mereka, mempunyai keunikan tersendiri dan menawarkan produk yang nyaman untuk dikenakan sehari-hari. Perusahaan menyebut produknya sebagai Life Wear, sederhana namun berkualitas. Uniqlo mendapat peringkat ketiga di produsen dan pengecer pakaian Global Utama.

\begin{tabular}{|l|l|c|c|c|c|}
\hline \multicolumn{1}{|c|}{$\begin{array}{c}\text { Company Name } \\
\text { (Filaghip Brand) }\end{array}$} & $\begin{array}{c}\text { Country } \\
\text { and Region }\end{array}$ & $\begin{array}{c}\text { End of } \\
\text { Fiscal Year }\end{array}$ & $\begin{array}{c}\text { Sales } \\
\text { (Irillion of } \\
\text { yen) }\end{array}$ & $\begin{array}{c}\text { Sales } \\
\text { (Billions } \\
\text { of dollar) }\end{array}$ & $\begin{array}{c}\text { Change (86) } \\
\text { (local base) }\end{array}$ \\
\hline INDITEX (ZARA) & Spain & Jan. 2020 & 3.55 & 33.68 & +8.2 \\
\hline Hennes \& Mauritz & Sweden & Nov. 2019 & 2.84 & 26.99 & +10.6 \\
\hline FAST RETAILING(UNIQLL) & Japan & Aug. 2020 & $\mathbf{2 . 0 1}$ & $\mathbf{1 9 . 0 6}$ & $-\mathbf{- 1 2 . 3}$ \\
\hline Gap & USA & Feb. 2020 & 1.73 & 16.38 & -1.2 \\
\hline Limited Brands & USA & Feb. 2020 & 1.36 & 12.91 & -2.4 \\
\hline PVH (Calvin Klein, Tommy Hilfiger) & USA & Feb. 2020 & 1.04 & 9.91 & +2.6 \\
\hline Ralph Lauren & USA & Mar. 2020 & 0.65 & 6.16 & -2.4 \\
\hline NEXT & UK & Jan. 2020 & 0.60 & 5.69 & +2.4 \\
\hline AMERICAN EAGLE OUTFITTERS & USA & Feb. 2020 & 0.45 & 4.31 & +6.8 \\
\hline Abercrombie \& Fitch & USA & Feb. 2020 & 0.38 & 3.62 & +0.9 \\
\hline Esprit & $\begin{array}{l}\text { Hong } \\
\text { Kong }\end{array}$ & Jun. 2020 & 0.13 & 1.19 & -21.1 \\
\hline
\end{tabular}

Gambar 1. Peringkat Produsen dan Pengecer Produk Pakaian Global Utama Sumber : Retailing 2020

Investasi digital Uniqlo sebagai strategi untuk mengejar ketinggalannya dalam perdagangan online juga dilakukan oleh Fast Retailing, yang dimotivasi oleh perubahan cara belanja konsumen selama pandemi Covid-19. Beberapa cara yang digunakan untuk memasarkan produknya secara online diantaranya adalah dengan website uniqlo.com/id/id dan di media sosial seperti facebook dan instagram yang dapat diakses konsumen dengan mudah.

Konsumen akan tertarik dengan content marketing Uniqlo yang informatif dan berusaha memberikan kepuasan kepada konsumen. Selain itu merek Uniqlo juga sudah dikenal luas oleh konsumen sehingga telah mempunyai pangsa pasar tersendiri yang sudah lama menggunakan merek ini. Hal ini membuat konsumen merasa mempunyai ikatan terhadap merek.

Dalam proses pembentukan ikatan antara merek dengan konsumen maka Uniqlo berusaha memberikan kesan yang baik pada konsumen karena akan memberikan pengetahuan emosional tersendiri. Pelanggan yang percaya dan puas dengan penggunaan merek menunjukkan bahwa customer engagementtelah berhasil dan menjadi keunggulan dari perusahaan.

Kepuasan konsumen yang tinggi setelah mempunyai pengalaman menggunakan produk Uniqlo akan mempengaruhi keputusan pembelian produk tersebut yang kedepannya akan menjadikan pembelian ulang (repeat purchase). Oleh 
karenanya perusahaan harus menciptakan kepercayaan kepada merek agar dapat melebihi ekspektasi konsumen sehingga menimbulkan sikap positif dan mempunyai keinginan untuk menggunakan kembali merek yang sama.

\section{METODE PENELITIAN}

\subsection{Content Marketing}

Content marketing merupakan suatu metode manajemen yang dilakukan perusahaan meliputi rekognisi, menelaah dan memuaskan keinginan konsumen agar dapat meraih keuntungan maksimal dengan memanfaatkan konten secara digital yang disebarkan melalui media digital (Dharmayanti \& Juventino, 2020).

Content marketing juga bermanfaat untuk mempengaruhi konsumen potensial dan dapat mengoptimalkan keterlibatan konsumen melalui pembentukan, pengedaran dan informasi konten yang sesuai, bermanfaat, penting dan mampu membuat konsumen menjadi percaya (Larissa, 2020).

Content marketing baiknya tidak hanya dapat menarik perhatian konsumen, namun juga dapat menampilkan informasi dan gambar atau foto yang dapat memberikan hiburan pada konsumen serta memberikan informasi yang akurat tentang produk yang ditawarkan (Nabilla \& Rubiyanti, 2020). Selain itu penggunaan content marketing oleh perusahaan untuk dapat meningkatkan kesadaran dari konsumen akan adanya merek sekaligus juga meningkatkan penjualan secara online.

\subsection{Brand Performance}

Brand performance (kinerja merek) merupakan bagaimana mengartikan suatu produk atau jasa yang bisa memuaskan keinginan konsumen dan sejauh mana produk atau jasa dapat berguna secara estetika serta mempunyai kualitas yang dapat bersaing dengan produk lain (Herdiany \& Yuliati, 2019).

Pemikiran atau ide tentang brand performance ini berkaitan dengan seberapa kuat posisi dari suatu merek di dalam pasar yang dapat terdeteksi melalui perolehan pangsa pasar, meningkatnya penjualan dan keuntungan yang didapatkan oleh perusahaan(Wijaya \& Dharmayanti, 2019).

Mengukur kinerja suatu merek akan melibatkan beberapa penilaian tentang bagaimana konsumen potensial akan membeli suatu produk. Kesadaran konsumen akan merek merujuk pada kecakapan target pasar mengidentifikasi merek atau produk secara cermat. Jika target pasar selalu memikirkan merek, maka dapat dipastikan konsumen akan terus datang untuk melakukan pembelian yang lebih banyak.

\subsection{Customer Engagement}

Customer engagement adalah terjadinya beberapa kali hubungan antara konsumen dengan merek yang bisa menguatkan dari segi emosional dan psikologis konsumen terhadap merek tersebut sehingga menimbulkan keterikatan(Santoso, 2020). Konsumen yang terikat dengan suatu produk dapat menjadi relasi yang dapat bekerja sama dengan perusahaan sehingga dapat menambah value produk tersebubt.

Dalam hal pemasaran secara online, customer engagement dimaksudkan agar dapat meningkatkan waktu dan perhatian yang diberikan oleh konsumen terhadap suatu merek di website atau di media sosial. Interaksi konsumen dengan produk melalui media onlineakan mendorong terciptanya komitmen antara konsumen dengan produsen.

Customer engagement memberikan konsumen pengaruh yang positif terhadap merek yang pada akhirnya akan menimbulkan repeat purchase sehingga setiap perusahaan pasti berusaha meningkatkan keterlibatan konsumen dengan produknya.

\subsection{Repeat Purchase}

Repeat Purchase (pembelian ulang) merupakan tindakan nyata dari konsumen dengan melakukan pembelian produk atau jasa yang sama lebih dari satu kali. Sebagian besar pembelian adalah pembelian ulang yang potensial (Larissa, 2020).

Keinginan konsumen untuk melakukan pembelian didasarkan pengalamannya menggunakan produk di masa lalu dan merasa puas. Semakin tinggi rasa puas yang didapatkannya pada pengalaman pembeliannya di masa lalu, akan semakin kuat keinginan itu untuk melakukan pembelian ulang, akan tetapi derajat kepuasan yang dirasakan setiap konsumen akan tidak sama (Wijaya \& Dharmayanti, 2019).

Repeat purchase juga didefinisikan sebagai tindakan konsumen yang loyal pada satu produk, yang akan melakukan pembelian ulang secara terus menerus dan menolak produk lain dari pesaing (Herdiany \& Yuliati, 2019).

\subsection{Jenis Penelitian}

Penelitian ini menggunakan pendekatan kuantitatif, yaitu menggunakan data statistik untuk menjawab pertanyaan

\subsection{Populasi dan Sampel}

Populasi merupakan total keseluruhan dari satuan-satuan atau individu-individu yang secara spesifik akan dilakukan penelitian. Satuan-satuan ini dinamakan unit analisi dan bisa merupakan manusia dan organisasi (Djarwnato, 1994). 
Sampel adalah bagian dari populasi yang dipelajari dalam sebuah penelitian atau riset dan hasilnya merupakan gambaran dari asal populasinya tetapi bukan populasi itu sendiri. Sampel yang digunakan dalam penelitian ini adalah konsumen yang pernah melakukan pembelian produk fashion merek Uniqlo dengan rentang usia 17 tahun ke atas.

\subsection{Teknik Pengambilan Sampel}

\section{Purposive Sampling}

Adalah cara mengambil sampel secara sengaja sesuai dengan syarat yang telah ditentukan oleh peneliti (Sugiyono, 2008). Dalam penelitian ini purposive sampling dilakukan dengan beberapa syarat, diantaranya :

- Pernah melakukan pembelian produk fashion merek Uniqlo lebih dari sekali

- Usia lebih dari 17 tahun

- Pendidikan minimal SMA

\section{Quota Sampling}

Merupakan teknik pengambilan sampel dari suatu populasi yang telah ditentukan untuk dikelompokkan sesuai dengan karakternya sampai mendapatkan jumlah quota yang diperlukan (Sugiyono, 2008). Quota sampling dalam penelitian ini ditentukan dengan karkter konsumen yang pernah melakukan pembelian produk fashion merek Uniqlo lebih dari satu kali. Dengan cara quota sampling maka didapatkan jumlah sampel sebanyak 100 orang.

\section{Insidental Sampling}

Merupakan teknik pengambilan sampel yang didasarkan pada kebetulan, yaitu siapa saja yang dijumpai secara kebetulan dengan peneliti dan bisa digunakan sebagai sampel apabila cocok dengan sumber data (Sugiyono, 2015).

\subsection{Definisi Operasional Variabel}

Definisi operasional variabel yang akan digunakan dalam penelitian ini adalah empat variabel yaitu :

\section{Content Marketing (X1)}

Variabel independen yang pertama adalah content marketing (X1), yaitu metode yang digunakan oleh perusahaan untuk memasarkan produk atau jasa dengan membuat dan menyebarluaskan konten yang mempunyai kualitas dan memikat konsumen agar konsumen dapat memahami pesan yang diterima sehingga akan memberikan dampak yang positif bagi perusahaan (Sanjaya, 2020). Content marketing dapat diukur dengan indikator yaitureader cognition, persuasions, decision making dan factors. Dalam penelitian ini content marketing diukur dengan indikator :

1. Strategy

2. Activity

3. Results

\section{Brand Performance (X2)}

Variabel independen yang kedua adalah brand performance (X2) yang berkaitan dengan seberapa kuat posisi suatu brand atau merek itu di dalam pasar dan pengukurannya dapat melalui pangsa pasar yang diperoleh, perkembangan penjualan dan keuntungan yang didapatan oleh perusahaan (Wijaya \& Dharmayanti, 2019).

Elemen-elemen dari brand performance menurut (Willianto.k \& Semuel.H, 2005) adalah product performance, service performance, customer care dan customer delight.

Dalam penelitian ini brand performance diukur dengan indikator :

1. Product performance

2. Service performance

3. Customer care

4. Customer satisfaction

5. Customer delight

\section{Customer Engagement $(Z)$}

Merupakan variabel intervening dalam penelitian ini yang didefinisikan oleh Wibowo \& Dharmayanti, (2020)sebagai suatu jenjang adanya keterikatan secara fisik,kognitif dan emosional konsumen dalam membina ikatan dengan perusahaan. Customer engagement pada penelitian ini diukur dengan indikator :

1. Identification

2. Enthusiasm

3. Attention

4. Absorption

5. Interaction

\section{Repeat Purchase}

Variabel dependen dalam penelitian ini adalah repeat purchase $(\mathrm{Y})$ yaitu perbuatan yang timbul karena reaksi pada obyek yang menunjukkan kebutuhan konsumen untuk membeli produk atau jasa secara berulang dan 
teratur(Santoso, 2020). Repeat purchase dapat diukur dengan indikator service relationship attributes, Relatoinship driving benefits dan motivational values.

Dalam penelitian ini repeat purchase diukur dengan indikator :

1. Commited customer

2. Trust

3. Loyal

\subsection{Pengumpulan Data}

Data dihimpun dan dikumpulkan melalui penyebaran kuesioner kepada responden agar didapatkan data yang diperlukan untuk penelitian ini. Setiap pertanyaan yang ada akan dilakukan pengukuran dengan menggunakan skala Likert yang dapat mengukur sikap, pendapat dan tanggapan seseorang atas suatu kejadian. Variabel-variabel dalam penelitian akan dijabarkan menjadi indikator variabel. Jawaban responden menurut skala Likert dalam penelitian ini adalah sangat setuju, setuju, cukup setuju, tidak setuju dan sangat tidak setuju yang diberi skor dengan angka 5, 4, 3, $2,, 1$. Skor keseluruhan dari setiap responden merupakan jumlah dari skor setiap jawaban dari responden tersebut.

\subsection{HIPOTESIS}

\section{Hubungan antara content marketing dengan customer engagement}

Penelitian yang dilakukan oleh Sanjaya, (2020)menyimpulkan bahwa content marketing memiliki pengaruh terhadap customer engagementsecara positif, dimana content marketing dari Pegipegi berhasil menyampaikan nilainilai dengan relevan sehingga mudah dimengerti oleh konsumennya. Demikian juga penelitian oleh Larissa, (2020) yang menyimpulkan bahwa content marketing berpengaruh signifikan terhadap customer engagement.

Penelitian oleh Dharmayanti \& Theofilus, (2019) juga menyimpulkan bahwa content marketing dari para brand yang menggunakan aplikasi Tiktok memiliki pengaruh terhadap customer engagement. Kesimpulan yang sama juga diberikan oleh Dharmayanti \& Juventino, (2020)yaitu content marketing dalam E-Commerce Zaloraberpengaruh ositif terhadap customer engagement. Dari hasil penelitian terdahulu diatasmaka peneliti dapat mengajukan Hipotesis 1 yaitu :

H1 : content marketing berpengaruh positif dan signifikan terhadap customer engagement pada konsumen produk fashion merek Uniqlo.

\section{Hubungan antara brand performance dengan customer engagement}

Penelitian oleh Wijaya \& Dharmayanti, (2019) menyimpulkan bahwa variabel brand performance dari Honda memiliki pengaruh terhadap customer engagement. Selain itu, penelitian oleh Hermanto \& Dharmayanti, (2020) juga menyimpulkan bahwa brand performance memiliki pengaruh pada customer engagement dan sekaligus memiliki dampak sigifikan.

Variabel brand performance memiliki pengaruh yang positif dan signifikan terhadap customer engagement juga merupakan kesimpulan dari penelitian oleh Herdiany \& Yuliati, (2019). Dari hasil penelitian terdahulu di atas maka peneliti dapat mengajukan Hipotesis 2 yaitu :

H2 : brand performanceberpengaruh positif dan signifikan terhadap customer engagement pada konsumen produk fashion merek Uniqlo.

\section{Hubungan antara content marketing dengan repeat purchase}

Penelitian oleh (Larissa, 2020) menyimpulkan bahwa content marketing mempunyai pengaruh yang signifikan terhadap repeat purchase. Kesimpulan yang sama juga dikemukakan oleh Santoso, (2020) dalam hasil penelitiannya yaitu content marketing berpengaruh signifikan terhadap repeat purchase. Dari hasil penelitian terdahulu di atas maka peneliti dapat mengajukan Hipotesis 3 yaitu :

H3 : content marketing berpengaruh positif dan signifikan terhadap repeat purchase pada konsumen produk fashion merek Uniqlo.

\section{Hubungan antara brand performance dengan repeat purchase}

Penelitian oleh Herdiany \& Yuliati, (2019) mengemukakan bahwa brand performance berpengaruh terhadap repeat purchase. Hasil penelitian oleh Kurniawan \& Harjati, (2017) menunjukkan bahwa terdapat pengaruh positif antara brand performance terhadap repeat purchase. Dari hasil penelitian terdahulu maka peneliti dapat mengajukan Hipotesis 4 yaitu :

H4 : brand performance berpengaruh positif dan signifikan terhadap repeat purchase pada konsumen produk fashion merek Uniqlo.

\section{Hubungan antara customer engagement dengan repeat purchase}

Penelitian oleh Sanjaya, (2020) menyimpulkan bahwa terdapat hubungan bernilai positif antara customer engagement terhadap repeat purchase. Penelitian oleh Santoso, (2020)juga menyimpulkan bahwa customer engagement mempunyai pengaruh positif terhadap repeat purchase.

Selain itu, penelitian oleh Larissa, (2020) juga menyatakan bahwa customer engagement berpengaruh sigifikan secara positif terhadap repeat purchase. Begitu juga penelitian oleh Wijaya \& Dharmayanti, (2019) yang 
menyimpulkan bahwa customer engagement mempunyai pengaruh positif terhadap repeat purchase. Dari hasil penelitian terdahulu maka peneliti dapat mengajukan Hipotesis 5 yaitu :

H5 : customer engagement berpengaruh positif dan signifikan terhadap repeat purchase pada konsumen produk fashion merek Uniqlo.

\section{HASIL DAN PEMBAHASAN}

\subsection{Uji Validitas}

Uji validitas dilakukan dalam setiap penelitian yang memakai kuesioner agar dapat diketahui valid tidaknya data yang diperoleh dari seluruh responden (Raharjo, 2017). Artinya bahwa apakah data yang sudah dikumpulkan dari jawaban responden terhadap pertanyaan dalam kuesioner tersebut sudah sesuai dengan maksud penelitian.

Uji Validitas Product Moment Pearson Corelation akan menghubungkan setiap skor item atau pertanyaan dengan jumlah skor secara keseluruhan yang didapatkan dari semua jawaban yang diberikan responden dalam kuesioner.

Pengambilan keputusan dilakukan dengan melakukan perbandingan antara nilai $r$ hitung dengan nilai $r$ tabel. Apabila $r$ hitung $>r$ tabel, maka semua pertanyaan dalam kuesioner adalah valid. Apabila $r$ hitung $<r$ tabel maka semua pertanyaan tersebut dinyatakan tidak valid.

Dari data kuesioner responden yang telah terkumpul maka kemudian dilakukan uji validitas. Hasil uji validitas pada tabel di bawah ini

Tabel 1. Uji Validitas Product Moment

\begin{tabular}{|c|c|c|c|}
\hline \multirow{2}{*}{ Nomor Item } & Pearson Correlation & \multirow{2}{*}{$\mathrm{r}_{\text {tabel }}$} & \multirow{2}{*}{ Interpretas } \\
\hline & $\left(\mathrm{r}_{\text {hitung }}\right)$ & & \\
\hline $\mathrm{X} 1.1$ & 0.786 & 0,396 & Item Valid \\
\hline $\mathrm{X} 1.2$ & 0.616 & 0,396 & Item Valid \\
\hline $\mathrm{X} 1,3$ & 0.603 & 0,396 & Item Valid \\
\hline X1.4 & 0.565 & 0,396 & Item Valid \\
\hline $\mathrm{X} 1.5$ & 0.769 & 0,396 & Item Valid \\
\hline $\mathrm{X} 2.1$ & 0,727 & 0,396 & Item Valid \\
\hline $\mathrm{X} 2.2$ & 0,401 & 0,396 & Item Valid \\
\hline $\mathrm{X} 2.3$ & 0,535 & 0,396 & Item Valid \\
\hline $\mathrm{X} 2.4$ & 0,782 & 0,396 & Item Valid \\
\hline $\mathrm{X} 2.5$ & 0,717 & 0,396 & Item Valid \\
\hline X2.6 & 0,761 & 0,396 & Item Valid \\
\hline $\mathrm{Z} 1.1$ & 0,558 & 0,396 & Item Valid \\
\hline $\mathrm{Z} 1.2$ & 0,773 & 0,396 & Item Valid \\
\hline $\mathrm{Z} 1.3$ & 0,681 & 0,396 & Item Valid \\
\hline Z1.4 & 0,511 & 0,396 & Item Valid \\
\hline $\mathrm{Z} 1.5$ & 0,733 & 0,396 & Item Valid \\
\hline Y1.1 & 0,506 & 0,396 & Item Valid \\
\hline Y1.2 & 0,560 & 0,396 & Item Valid \\
\hline Y1.3 & 0,878 & 0,396 & Item Valid \\
\hline Y1.4 & 0,692 & 0,396 & Item Valid \\
\hline
\end{tabular}

Dari Tabel 1 Uji Validitas Product Moment diketahui bahwa hasil penghitungan $r$ hitung untuk semua item adalah lebih besar dari $r$ tabel, sehingga semua pertanyaan dalam kuesioner dinyatakan valid.

\subsection{Uji Reliabilitas}

Uji Reliabilitas Alpha Cronbach's dilakukan sopaya seluruh pertanyaan dalam kuesioner yang digunakan dalam penelitian dapat dipercaya sebagai alat pengumpul data. Uji reliabilitas bertujuan untuk mengetahui tingkat konsistensi suatu angket yang dipakai oleh peneliti, agar dapat digunakan kehandalannya dalam mengukur variabel penelitian, dimanapun penelitian ini dilakukan dan secara berulang-ulang ataupun dengan kuesioner yang sama (Raharjo, 2017).

Uji reliabilitas dapat dilakukan secara bersama-sama terhadap seluruh item pertanyaan dalam kuesioner penelitian (Sujarweni, 2014).

Pengambilan keputusan yang digunakan sebagai dasar dalam uji reliabilitas ini adalah jika nilai cronbach's alpha < 0,6 maka kuesioner dikatakan reliabel atau konsisten. Sedangkan jika nilai cronbach's alpha $<0,6$ maka kuesioner dikatakan tidak reliabel atau tidak konsisten. Dalam penelitian ini, uji reliabilitas alpha cronbach's adalah dalam tabel berikut ini : 
Ekonomi, Keuangan, Investasi dan Syariah (EKUITAS)

Vol 3, No 2, November 2021, Hal 251-262

ISSN 2685-869X (media online)

DOI 10.47065/ekuitas.v3i2.1160

Tabel 2. Uji Realiblitas Alpha Cronbach's

\begin{tabular}{|c|c|c|c|c|}
\hline & \multicolumn{4}{|c|}{ Item-Total Statistics } \\
\hline & $\begin{array}{l}\text { Scale Mean if } \\
\text { Item Deleted }\end{array}$ & $\begin{array}{l}\text { Scale Variance } \\
\text { if Item Deleted }\end{array}$ & $\begin{array}{l}\text { Corrected Item- } \\
\text { Total Correlation }\end{array}$ & $\begin{array}{c}\text { Cronbach's } \\
\text { Alpha if Item } \\
\text { Deleted }\end{array}$ \\
\hline$X 1.1$ & 74.48 & 88.093 & .753 & .922 \\
\hline $\mathrm{X} 1.2$ & 74.64 & 92.240 & .574 & .926 \\
\hline$X 1.3$ & 74.88 & 91.277 & .553 & .926 \\
\hline$X 1.4$ & 74.56 & 92.423 & .515 & .927 \\
\hline$\times 1.5$ & 75.40 & 83.917 & .718 & .924 \\
\hline$\times 2.1$ & 74.40 & 90.167 & .691 & .924 \\
\hline$\times 2.2$ & 74.64 & 94.990 & .345 & .930 \\
\hline$\times 2.3$ & 74.48 & 92.510 & .480 & .928 \\
\hline$\times 2.4$ & 75.28 & 82.043 & .727 & .924 \\
\hline$\times 2.5$ & 74.84 & 88.473 & .673 & .924 \\
\hline$\times 2.6$ & 74.88 & 88.193 & .724 & .923 \\
\hline $\mathrm{Z1.1}$ & 74.56 & 93.840 & .519 & .927 \\
\hline $\mathrm{Z1.2}$ & 74.76 & 91.690 & .750 & .924 \\
\hline Z1.3 & 74.64 & 91.407 & .645 & .925 \\
\hline Z1.4 & 74.48 & 91.927 & .445 & .929 \\
\hline $\mathrm{Z1.5}$ & 74.76 & 90.273 & .699 & .924 \\
\hline Y1.1 & 74.92 & 92.577 & .446 & .929 \\
\hline Y1.2 & 75.04 & 93.790 & .520 & .927 \\
\hline Y1.3 & 74.88 & 85.527 & .856 & .920 \\
\hline Y1.4 & 75.16 & 91.140 & .656 & .925 \\
\hline
\end{tabular}

Hasil pengujian pada Tabel 2 menunjukkan bahwa semua item dalam variabel content marketing, brand performance, customer engagement dan repeat purchase memiliki nilai Cronbach's Alpha $>0,6$. Maka dapat disimpulkan bahwa semua item dalam variabel penelitian dinyatakan reliabel.

\subsection{Hasil Penelitian}

\subsubsection{Uji Asumsi Klasik}

1. Uji NormalitasOne Sample Kolmogorof-Smirnov

Uji Normalitas dilakukan untuk mengetahui apakah data penelitian terdistribusi secara normal atau tidak. Regresi dinyatakan memenuhi asumsi normalitas apabila nilai Asymp sig > 0,05. Hasil uji Normalitas terdapat dalam tabel 3 berikut.

Tabel 3. One Sample Kolmogorof Smirnof Test

\begin{tabular}{llr}
\hline \multicolumn{2}{c}{ One-Sample Kolmogorov-Smirnov Test } \\
\hline $\mathrm{N}$ & \multicolumn{2}{c}{ Unstandardized Residual } \\
\hline Normal Parameters & 93 \\
& Mean & .0000000 \\
Most Extreme Differences & Std. Deviation & 1.76388721 \\
& Absolute & .081 \\
& Positive & .048 \\
Test Statistic & Negative & -.081 \\
Asymp. Sig. (2-tailed) & .081 \\
\hline a. Test distribution is Normal. & $.164^{\mathrm{c}}$ \\
\hline b. Calculated from data. \\
c. Lilliefors Significance Correction.
\end{tabular}

Dari Tabel 3 nilai Asymp sig adalah 0,164 >0,05 sehingga dinyatakan bahwa data terdistribusi normal.

\subsubsection{Uji Multikolinearitas}

Untuk menguji apabila dalam model regresi ditemukan adanya korelasi (hubungan yang kuat) antara variabel independen. Pada model regresi yang baik seharusnya tidak terjadi korelasi diantara variabel independen.

Gejala multikolienearitas diketahui dari nilai Tolerance dan VIF. Apabila nilai tolerance $>0,1$ dan VIF $<10$ maka model regresi tidak terdapat masalah multikolinearitas. Hasil uji Multikolinearitas dapat dilihat pada tabel 4 berikut ini. 
Tabel 4. Uji Multikolinearitas

\begin{tabular}{|c|c|c|c|c|c|c|c|c|}
\hline \multicolumn{9}{|c|}{ Coefficients $^{a}$} \\
\hline \multirow{2}{*}{\multicolumn{2}{|c|}{ Model }} & \multicolumn{2}{|c|}{$\begin{array}{l}\text { Unstandardized } \\
\text { Coefficients }\end{array}$} & \multirow{2}{*}{$\begin{array}{c}\text { Standardized } \\
\text { Coefficients } \\
\text { Beta } \\
\end{array}$} & \multirow[b]{2}{*}{$t$} & \multirow[b]{2}{*}{ Sig. } & \multicolumn{2}{|c|}{$\begin{array}{l}\text { Collinearity } \\
\text { Statistics }\end{array}$} \\
\hline & & B & Std. Error & & & & Tolerance & VIF \\
\hline \multirow[t]{4}{*}{1} & (Constant) & ,988 & 1,199 & & ,824 & ,412 & & \\
\hline & $\mathrm{x} 1$ & ,267 & ,078 & ,356 & 3,411 & ,001 & ,356 & 2,805 \\
\hline & $\mathrm{X} 2$ & ,172 & ,061 & ,258 & 2,814 & ,006 & ,463 & 2,161 \\
\hline & Z & ,262 & ,098 & 281 & 2,674 & ,009 & ,352 & 2,838 \\
\hline
\end{tabular}

Dari Tabel 4 di atas maka seluruh variabel independen X1 dan X2 memiliki nilai Tolerance > 0,1 dan VIF < 10 yang menunjukkan tidak adanya korelasi yang tinggi diantara variabel independen, sehingga model regresi sudah dapat memenuhi asumsi multikolinearitas.

\subsubsection{Uji Heteroskedastisitas}

Untuk menguji apabila di dalam model regresi terjadi ketidaksamaan variasi dari nilai residual satu pengamatan ke pengamatan lainnya. Hasil Uji heteroskedastisitas dapat dilihat pada Tabel 5 berikut ini.

Tabel 5. Uji Heteroskedastisitas

\begin{tabular}{|c|c|c|c|c|c|c|}
\hline \multicolumn{7}{|c|}{ Coefficients $^{a}$} \\
\hline \multirow[b]{2}{*}{ Model } & & \multicolumn{2}{|c|}{ Unstandardized Coefficients } & \multirow{2}{*}{$\begin{array}{c}\text { Standardized } \\
\text { Coefficients } \\
\text { Beta } \\
\end{array}$} & \multirow[b]{2}{*}{$\mathrm{t}$} & \multirow[b]{2}{*}{ Sig. } \\
\hline & & B & Std. Error & & & \\
\hline \multirow[t]{4}{*}{1} & (Constant) & 1,834 & ,782 & & 2,344 &, 02 \\
\hline & $\mathbf{x} 1$ &,- 036 &, 051 &,- 124 &,- 714 &, 47 \\
\hline & $\mathrm{X} 2$ &, 060 &, 040 & ,230 & 1,507 &, 13 \\
\hline & $z$ &,- 063 & 064 &,- 172 &,- 984 & ,32 \\
\hline
\end{tabular}

a. Dependent Variable: AbsRes

Dari Tabel 5 di atas diperoleh nilai Absolut Residual dari seluruh variabel adalah tidak signifikan (Sig > $0,05)$, sehingga model regresi tidak mengandung masalahheteroskedastisitas.

\subsubsection{Uji Analisis Jalur (Path Analysis)}

Berfungsi untuk menguji apakah variabel independen yaitu content marketing (X1), dan brand performance (X2)berpengaruh langsung terhadap variabel dependen yaitu repeat purchase (Y). Selain itu uji ini juga memberi penjelasan tentang ada atau tidaknya pengaruh tidak langsung dari variabel independen melalui variabel intervening yaitu customer engagement.

\subsection{Regresi Model I}

Tabel 6. Coefficient Regresi

\section{Coefficients $^{a}$}

\begin{tabular}{lr|r|r|r|r|r}
\multicolumn{2}{c}{} & Unstandardized Coefficients & Standardized Coefficients & & \\
Model & B & Std. Error & Beta & t & Sig. \\
\hline 1 (Constant) & 5,761 & 1,136 & & & 5,072 &, 000 \\
\hline X1 &, 453 &, 069 &, 565 & 6,553 &, 000 \\
\hline X2 &, 217 &, 062 &, 304 & 3,522 &, 001 \\
\hline
\end{tabular}

a. Dependent Variable: Z

Model persamaan regresi disusun sesuai hasil koefisien regresi pada tabel di atas yaitu :

$$
\mathrm{Z}=5,761+0,453 \mathrm{X}_{1}+0,217 \mathrm{X}_{2}
$$

\section{a. Analisis Pengaruh X1 terhadap Z}

Pada tabel Coefficient di atas dapat diketahui nilai signifikasi variabel $\mathrm{X} 1=0,000$ lebih kecil dari 0,05 , yang memberikan kesimpulan bahwa variabel X1 berpengaruh positif signifikan terhadap variabel $\mathrm{Z}$.

b. Analisis Pengaruh X2 terhadap Z

Pada tabel coefficient di atas juga ditunjukkan bahwa nilai signifikan dari variabel X2 $=0,001$ lebih kecil dari 0,005 yang memberikan kesimpulan bahwa variabel X2 berpengaruh positif dan signifikan terhadap variabel $\mathrm{Z}$. 
Beta $\mathrm{I}=0,565$, Beta $2=0,304$. Sedangkan e1 adalah $\sqrt{ }(1-0,648)=0,593$. Sehingga dapat diperoleh diagram jalur model struktur I sebagai berikut :

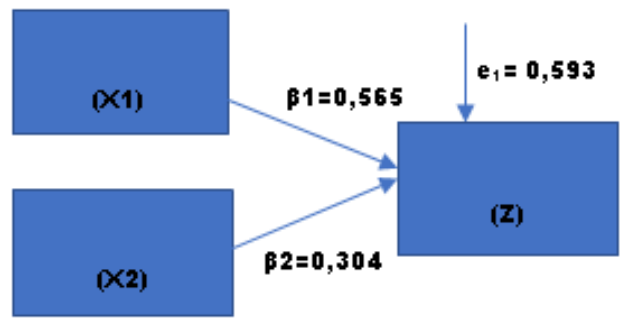

Gambar 2. Model Struktur I

\subsubsection{Uji Model}

Digunakan untuk melihat seberapa pengaruh variabel independen terhadap variabel dependen.

Tabel 7. Koefisien Determinasi

\begin{tabular}{lr|r|r|r} 
& & \multicolumn{3}{c}{ Model Summary } \\
Model & $\mathrm{R}$ & R Square & \multicolumn{1}{c}{$\begin{array}{c}\text { Adjusted R } \\
\text { Square }\end{array}$} & $\begin{array}{c}\text { Std. Error of } \\
\text { the Estimate }\end{array}$ \\
\hline 1 &, $805^{\mathrm{a}}$ &, 648 &, 640 & 1,92676 \\
\hline
\end{tabular}

a. Predictors: (Constant), X2, X1

Dari tabel diatas diperoleh nilai koefisien determinasi (R square) adalah 0,640 atau 64\%, berarti bahwa variabel independen mampu menjelaskan perubahan-perubahan pada variabel independen sebesar $64 \%$, sedangkan sisanya sebesar $36 \%$ merupakan pengaruh faktor lain yang tidak diteliti.

\subsection{Regresi Model II}

Tabel 8. Coefficient Regresi II

\begin{tabular}{|c|c|c|c|c|c|c|c|c|}
\hline \multicolumn{9}{|c|}{ Coefficients $^{a}$} \\
\hline & & \multicolumn{2}{|c|}{$\begin{array}{l}\text { Unstandardized } \\
\text { Coefficients }\end{array}$} & \multirow{2}{*}{$\begin{array}{c}\text { Standardized } \\
\text { Coefficients } \\
\text { Beta }\end{array}$} & \multirow[b]{2}{*}{$t$} & \multirow[b]{2}{*}{ Sig. } & \multicolumn{2}{|c|}{$\begin{array}{l}\text { Collinearity } \\
\text { Statistics }\end{array}$} \\
\hline \multicolumn{2}{|c|}{ Model } & B & Std. Error & & & & Tolerance & VIF \\
\hline 1 & (Constant) & ,988 & 1,199 & & ,824 & ,412 & & \\
\hline & $\mathrm{X} 1$ & ,267 & 078, & 356 & 3,411 & ,001 & ,356 & 2,805 \\
\hline & $\mathrm{X} 2$ & ,172 & ,061 & 258 & 2,814 & ,006 & ,463 & 2,161 \\
\hline & $z$ & ,262 & ,098 & ,281 & 2,674 & ,009 & ,352 & 2,838 \\
\hline
\end{tabular}

a. Dependent Variable: $Y$

Dari tabel coefficient regresi II dapat disusun model persamaan regresi adalah :

$$
\mathrm{Y}=0,988+0,267 \mathrm{X} 1+172 \mathrm{X} 2+0,262 \mathrm{Z}
$$

Koefisien determinasi (R square) dalam analisi Regresi II dapat dilihat dalam Tabel 10 berikut

Tabel 9. Koefisien Determinasi Regresi II

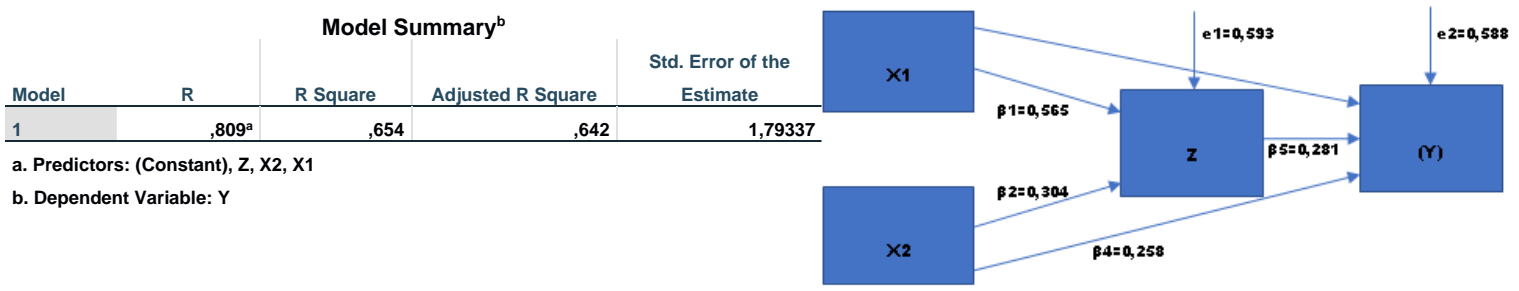

Dari Tabel 9, nilai koefisien korelasi (R Square) adalah 0,642 atau 64,2\% yang menunjukkan bahwa variabel $\mathrm{X} 1, \mathrm{X} 2$ dan Z mampu menjelaskan perubahan-perubahan pada variabel Y sebesar $64,2 \%$, sedangkan sisanya sebesar $35,8 \%$ adalah pengaruh faktor lain yang tidak diteliti.

\section{a. Analisis Pengaruh X1 terhadap Y}

Berdasarkan output Regresi Model II pada Tabel Coefficients maka nilai signifikasi dari variabel X1 $=0,001$, menunjukkan bahwa variabel X1 (content marketing) berpengaruh positif signifikan terhadap variabel Y (repeat purchase) 


\section{b. Analisis Pengaruh X2 terhadap Y}

Berdasarkan output Regresi Model II pada Tabel Coefficients maka nilai signifikasi dari variabel X2 $=0,006$, menunjukkan bahwa variabel X2 (brand performance) berpengaruh positif signifikan terhadap variabel $\mathrm{Y}$ (repeat purchase)

\section{c. Analisis Pengaruh $\mathrm{Z}$ terhadap $\mathrm{Y}$}

Berdasarkan output Regresi Model II pada Tabel Coefficients maka nilai signifikasi dari variabel $\mathrm{Z}=0,009$, menunjukkan bahwa variabel $\mathrm{Z}$ (customer engagement) berpengaruh positif signifikan terhadap variabel $\mathrm{Y}$ (repeat purchase).

Beta 3 adalah 0,356 Beta 4 adalah 0,258, Beta 5 adalah 0,281 dan e2 adalah $\sqrt{ }(1-0,654)=0,588$. Dari hasil analisis regresi model II dapat dilihat diperoleh diagram jalur model struktur II sebagai berikut :

\section{d. Uji Efek Mediasi}

\section{- Pengaruh content marketing (X1) terhadap repeat purchase (Y) melalui customer engagement (Z).}

Tabel 10. Uji Mediasi X1 melalui Z terhadap $Y$

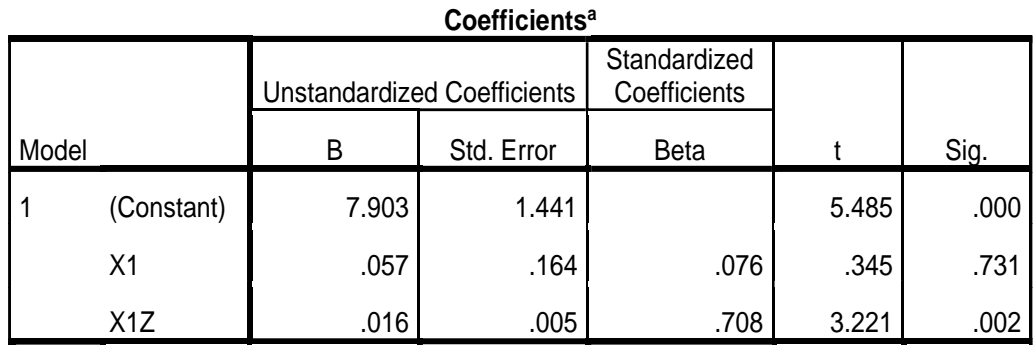

a. Dependent Variable: $Y$

Tabel 10 menunjukkan hasil uji mediasi adalah sig $0,002<0,05$ yang berarti bahwa pengaruh variabelmediasi adalah signifikan. Nilai koefisien jalur X1 terhadap Y $(\beta 3)$ adalah 0,076 sedangkan nilai koefisien jalur X1 terhadap Y melalui Z $(\beta 1 \times \beta 5)$ adalah 0,708 . Karena $\beta 3<(\beta 1 \times \beta 5)$ maka disimpulkan bahwa pengaruh content marketing terhadap repeat purchase akan lebih efektif melalui customer engagement dibandingkan pengaruh langsung. Dengan demikian, variabel customer engagement terbukti efektif dalam memediasi pengaruh dari content marketing terhadap repeat purchase.

\section{- Pengaruhbrand performance}

Tabel 11. Uji Mediasi X2 melalui Z terhadap Y

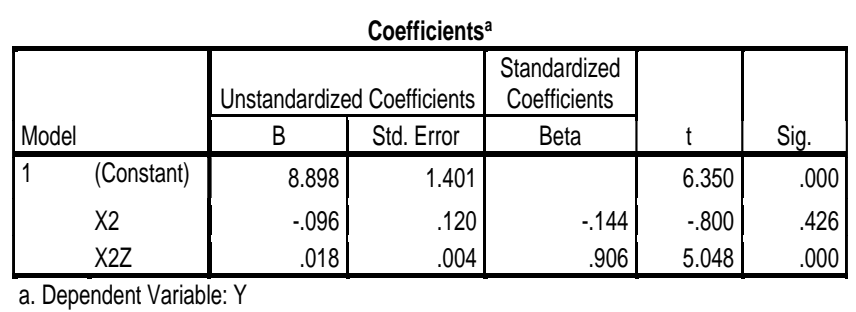

Tabel 11 menunjukkan hasil uji mediasi adalah sig $0,000<0,05$ yang berarti bahwa pengaruh variabel mediasi adalah signifikan. Nilai koefisien jalur X2 terhadap Y ( $\beta 4)$ adalah 0,144 sedangkan nilai koefisien jalur X2 terhadap Y melalui $Z(\beta 2 \times \beta 5)$ adalah 0,906 . Karena $\beta 4<(\beta 2 \times \beta 5)$ maka disimpulkan bahwa pengaruh brand performance terhadap repeat purchase akan lebih efektif melalui customer engagement dibandingkan pengaruh langsung. Dengan demikian, variabel customer engagement terbukti efektif dalam memediasi pengaruh dari brand performance terhadap repeat purchase.

\subsection{Pembahasan}

\section{a. Pengaruh content marketing terhadap customer engagement}

Hasil pengujian yang dilakukan mendapatkan hasil nilai signifikasi variabel content marketing (X1) terhadap customer engagement $(\mathrm{Z})$ sebesar $0,000<0,05$, membuktikan bahwa content marketingsecara langsungberpengaruh positif dan sigifikan terhadap customer engagement. Sehingga tiga indikator dalam content marketing yaitu strategy, activity dan results dapat memberikan pengaruh yang positif kepada customer engagementkonsumen produk fashion merek Uniqlo.

Maka penelitian ini berhasil membuktikan Hipotesis 1 : Ada pengaruh positif dan signifikan content marketingterhadap customer engagementpada konsumen produk fashion merek Uniqlo. Pembuktian tersebut didukung oleh penelitian oleh Larissa, (2020) yang menyatakan bahwa content marketing berpengaruh signifikan secara positif terhadap customer engagement pada pengguna Traveloka Surabaya. 
Dapat disimpulkan bahwa isi dari konten pemasaran produk Uniqlo membuat konsumen merasa mempunyai keterikatan terhadap produk tersebut.

\section{b. Pengaruh brand performance terhadap customer engagement}

Hasil pengujian yang dilakukan mendapatkan hasil nilai signifikasi variabel brand performance(X2) terhadap customer engagement (Z) sebesar $0,001<0,05$, membuktikan bahwa brand performance secara langsungberpengaruh positif dan sigifikan terhadap customer engagement. Sehingga lima indikator dalam brand performance yaitu product performance, service performance, customer care, customer satisfaction dan customer delight dapat memberikan pengaruh yang positif kepada customer engagementkonsumen produk fashion merek Uniqlo.

Maka penelitian ini berhasil membuktikan Hipotesis 2 : Ada pengaruh positif dan signifikan brand performance terhadap customer engagementpada konsumen produk fashion merek Uniqlo. Pembuktian tersebut didukung oleh penelitian olehHerdiany \& Yuliati, (2019) yang menyatakan bahwa brand performanceberpengaruh secara positif dan signifikan terhadap customer engagement Apple iPhone.

Dapat disimpulkan bahwa brand performance atau kinerja merek produk Uniqlo membuat konsumen merasa mempunyai keterikatan terhadap produk tersebut.

\section{c. Pengaruh content marketing terhadap repeat purchase}

Berdasarkan hasil pengujian, didapatkan hasil nilai signifikasi variabel content marketing (X1) terhadap repeat purchase $(\mathrm{Y})$ sebesar $0,001<0,05$, membuktikan bahwa content marketingsecara langsungberpengaruh positif dan sigifikan terhadap repeat purchase.

Maka penelitian ini berhasil membuktikan Hipotesis 3 : Ada pengaruh positif dan signifikan content marketingterhadap repeat purchasepada konsumen produk fashion merek Uniqlo. Pembuktian tersebut didukung oleh penelitian oleh(Ramadhany, et all, (2021) yang menyatakan bahwa content marketing berpengaruh positif dan signifikan terhadap customer engagement pada konsumen Bajumantanmoo

Dapat disimpulkan bahwa isi dari konten pemasaran produk Uniqlo membuat konsumen kemudian melakukan pembelian ulang untuk produk tersebut.

\section{d. Pengaruh brand performance terhadap repeat purchase}

Berdasarkan hasil pengujian, didapatkan hasil nilai signifikasi variabel brand performnce $(\mathrm{X} 2)$ terhadap repeat purchase $(\mathrm{Y})$ sebesar $0,006<0,05$, membuktikan bahwa brand performncesecara langsungberpengaruh positif dan sigifikan terhadap repeat purchase.

Maka penelitian ini berhasil membuktikan Hipotesis 4: Ada pengaruh positif dan signifikan brand performanceterhadap repeat purchase pada konsumen produk fashion merek Uniqlo. Pembuktian tersebut didukung oleh penelitian olehKurniawan \& Harjati, (2017) yang menyatakan bahwa brand performanceberpengaruh positif dan signifikan terhadap repeat purchasesmatrphone produk Xiaomi.

Dapat disimpulkan bahwa brand performance (kiberja merek) produk Uniqlo membuat konsumen kemudian melakukan pembelian ulang untuk produk tersebut.

\section{e. Pengaruh customer engagementterhadap repeat purchase}

Berdasarkan hasil pengujian, didapatkan hasil nilai signifikasi variabel customer engagement $(Z)$ terhadap repeat purchase (Y) sebesar 0,009<0,05, membuktikan bahwa customer engagementsecara langsungberpengaruh positif dan sigifikan terhadap repeat purchase.

Maka penelitian ini berhasil membuktikan Hipotesis 5 : Ada pengaruh positif dan signifikan customer engagement terhadap repeat purchase pada konsumen produk fashion merek Uniqlo. Pembuktian tersebut didukung oleh penelitian olehWijaya \& Dharmayanti, (2019) yang menyatakan bahwa customer engagement berpengaruh positif dan signifikan terhadap repeat purchase penggunasepeda motor Honda di Surabaya.

Dapat disimpulkan bahwa keterikatan konsumen terhadap produk Uniqlo membuat konsumen kemudian melakukan pembelian ulang untuk produk tersebut.

\section{KESIMPULAN}

Analisis dan pembahasan yang telah dilakukan memberikan beberapa kesimpuan Content marketing (X1)berpengaruh positif dan signifikan terhadap customer engagement (Z), dibuktikan dengan nilai koefisien Beta sebesar 0,565 atau sebesar 56,5\% dan nilai probabilitas 0,000 (p<0,05). Brand performance (X2)berpengaruh positif dan signifikan terhadap customer engagement $(\mathrm{Z})$, dibuktikan dengan nilai koefisien Beta sebesar 0,304 atau sebesar $30,4 \%$ dan nilai probabilitas $0,001(\mathrm{p}<0,01)$. Content marketing (X1) berpengaruh positif dan signifikan terhadaprepeat purchase (Y), dibuktikan dengan nilai koefisien Beta sebesar 0,356 atau sebesar 35,6\% dan nilai probabilitas 0,001 $(\mathrm{p}<0,01)$. Brand performance (X2) berpengaruh positif dan signifikan terhadaprepeat purchase (Y), dibuktikan dengan nilai koefisien Beta sebesar 0,258 atau sebesar 25,8\% dan nilai probabilitas 0,006 ( $<<0,06)$. Customer engagement $(\mathrm{Z})$ berpengaruh positif dan signifikan terhadap repeat purchase $(\mathrm{Y})$, dibuktikan dengan nilai koefisien Beta sebesar 0,281 atau sebesar 28,1\% dan nilai probabilitas 0,009 ( $<<0,09)$.. 
Ekonomi, Keuangan, Investasi dan Syariah (EKUITAS)

Vol 3, No 2, November 2021, Hal 251-262

ISSN 2685-869X (media online)

DOI 10.47065/ekuitas.v3i2.1160

\section{REFERENCES}

Abdullah, A.H dan Kesmuwati, Ayundyah. (2018). Analisis Kepuasan pelanggan Terhadap elayanan Astra Motor Yogyakarta Bagian H1 Penjualan Unit Sepeda Motor. Statistika, 18(2), 113-121.

Arikunto, Suharsimi. (2016). Prosedur Penelitian Suatu Pendekatan Praktik. Jakarta: Rineka Cipta

Fraering, M. and Minor, M.S. (2013). Beyond Loyalty: Customer Satisfaction, Loyality, and Fortitude. Journal of Service Marketing, 27(4), 334-344.

Kotler, P. and Keller, K.L. (2012). Marketing Management 14th Edition. Pearson Education Inc, United State of America

Ningsi, Besse Arnawisuda dan Agustina, Lucia. (2018). Analisis Kepuasan Pelanggan Atas Kualitas Produk dan Pelayanan Dengan Metode SEM-PLS. Jurnal Statistika dan Aplikasinya (JSA), 2(2), 8-16.

Pambudy, A. P., \& Syairozi, M. I. (2019). Analisis Peran Belanja Modal dan Investasi Swasta Terhadap Pertumbuhan Ekonomi Serta Dampaknya Pada Kesejahteraan Masyarakat. Jurnal Ekonomi dan Bisnis, 20(1), 26-39.

Ruswaji, R., \& Sulaeman, M. M. (2021). DEVELOPMENT AND INNOVATION OF SENDANG BATIK DESIGN AND MOTIVATION DURING THE NEW NORMAL TIME WITH SIWALAN LEAF AND FRUIT MOTIF. JHSS (JOURNAL OF HUMANITIES AND SOCIAL STUDIES), 5(3), 326-329.

Saumi, Tia Fitria dan Panudju, Andreas Tri. (2018). Analisis Korespondensi Ordinal Untuk Mengevaluasi Tingkat Kepuasan Konsumen. Statmat (Jurnal Statistik dan Matematika), 2(1), 94-102.

Syairozi, M. I. (2021). Analisis Kemiskinan di Sektor Pertanian (Studi Kasus Komoditas Padi di Kabupaten Malang). Media Ekonomi, 28(2), 113-128.

Tjiptono, F., \& Chandra, G. (2011). Service, Quality \& Satisfaction (3rd ed.). Yogyakarta : ANDI

Wijaya, K., \& Syairozi, M. I. (2020). Analisis perpindahan tenaga kerja informal Kabupaten Pasuruan. Jurnal Paradigma Ekonomika, 15(2), 173-182. 